\title{
Utilização de macrófitas aquáticas de três diferentes tipos ecológicos para remoção de Escherichia coli de efluentes de criação de pacu
}

\author{
Use of aquatic plants of three different ecological types \\ for Escherichia coli removal from pacu breeding effluents
Argos Willian de Almeida Assunção', Pedro Gatti Junior', Renata Vilar Almeida², Yuri Gasparotto ${ }^{3}$, Luiz Augusto do Amaral ${ }^{4}$

\begin{abstract}
RESUMO
O presente trabalho avaliou a contaminação por Escherichia coli em viveiro de criação de pacu (Piaractus mesopotamicus) esua remoção do efluente utilizando um sistema do tipo constructed wetland, contendo macrófitas aquáticas de três tipos ecológicos diferentes (Eichhornia crassipes, Ceratophyllum demersum e Typha domingensis). Durante três meses foram realizadas análises do número mais provável (NMP) de Escherichia coli na água de abastecimento do viveiro, no seu efluente e em cada etapa do tratamento (sedimentação e emprego de cada espécie de macrófita). Concluiu-se que a contaminação por E. coli na água de abastecimento e no viveiro pode alcançar o ambiente por meio do efluente. O sistema de tratamento proposto foi eficiente na remoção de $E$. coli da água, sendo que, após estabilização do sistema, ocorreu remoção média de 95\% da contaminação. A etapa contendo E. crassipes apresentou maior remoção média, porém mostrou diminuição da eficiência a partir de 60 dias após implementação do sistema. A remoção média das etapas contendo $C$. demersum e $T$. domingensis foi prejudicada devido à presença de E. coli no solo usado como substrato durante as primeiras semanas de experimento. Contudo, com a diminuição do efeito da contaminação presente no substrato, essas duas etapas foram fundamentais para manutenção da qualidade do efluente tratado, demonstrando que o consórcio de espécies de tipos ecológicos diferentes foi vantajoso, uma vez que a qualidade da água do efluente foi mantida mesmo quando algumas etapas do tratamento diminuíram sua eficiência.
\end{abstract}

Palavras-chave: piscicultura; qualidade de água; tratamento de efluente; wetland construída.

\begin{abstract}
This study evaluated the water contamination by Escherichia coli in pacu (Piaractus mesopotamicus) breeding ponds and its removal by a constructed wetland system containing macrophytes of three different ecological types (Eichhornia crassipes, Ceratophyllum demersum, and Typha domingensis). The most probable number of $E$. coli in the water was quantified for supply site, effluent and at each stage of treatment (sedimentation and use of each type of aquatic macrophyte). We conclude that $E$. coli contamination in water supply and in fishpond can reach the environment through the effluent. The proposed treatment system was efficient in removing $E$. coli from the water, and when the system was stabilized the average removal efficiency of $E$. coli was $95 \%$. The tank containing E. crassipes showed the highest removal average, even though it exhibited an efficiency reduction after 60 days of experiment. The average removal of the tanks containing $C$. demersum and $T$. domingensis was hampered due to the presence of $E$. coli in soil used as substrate. However, after the decrease of substrate contamination effect, these two plants were essential for the maintenance of water quality of the treated effluent, indicating the benefits of aquatic macrophytes diversity in treatment systems. The effluent quality was maintained even when some system steps presented a decrease of removal efficiency.
\end{abstract}

Keywords: pisciculture; water quality; effluent treatment; constructed wetland.

'Pós-graduando em Aquicultura pelo Centro de Aquicultura da Universidade Estadual Paulista “Júlio de Mesquita Filho” (Unesp) - Jaboticabal (SP), Brasil. 2Pós-graduanda em Ecologia e Recursos Naturais pela Universidade Federal de São Carlos (UFSCar) - São Carlos (SP), Brasil. ${ }^{3}$ Biólogo na Faculdade de Ciências Agrárias e Veterinárias da Unesp - Jaboticabal (SP), Brasil.

${ }^{4}$ Professor Adjunto do Departamento de Medicina Veterinária Preventiva da UNESP e do Centro de Aquicultura da Unesp - Jaboticabal (SP), Brasil. Endereço para correspondência: Argos Willian de Almeida Assunção - Departamento de Biologia - FFLCRP - Universidade de São Paulo - Av. Bandeirantes, 3900 Bairro Monte Alegre - Ribeirão Preto (SP) - 14014-901. E-mail: argos_willian@yahoo.com.br Recebido: 22/12/14 - Aceito: 22/07/16 - Reg. ABES: 144278 


\section{INTRODUÇÃO}

Diversos trabalhos indicam a piscicultura como atividade impactante na qualidade da água e demonstram os riscos relacionados ao descarte dos efluentes sem tratamento prévio em corpos hídricos receptores (AYROZA et al., 2013; STEPHENS \& FARRIS, 2004; YUCEL-GIER et al., 2007), podendo aumentar a ocorrência de organismos patogênicos já estabelecidos no ambiente e introduzir novos patógenos (THOMPSON et al., 2002). Além disso, a presença de organismos patogênicos em viveiros de produção pode causar contaminação do pescado produzido, bem como aumentar os riscos de contaminação cruzada durante seu armazenamento e processamento (GATTI JUNIOR et al., 2014; LORENZON et al., 2010; SUHALIM et al., 2007).

A presença de contaminantes ou poluentes (químicos ou biológicos) pode desqualificar um efluente de produção e impedir o seu despejo em um corpo hídrico receptor. Sendo assim, um sistema de tratamento representa um processo importante para a melhoria da qualidade da água residual, além de implementar cultivos mais sustentáveis. Diversos tipos de sistemas de tratamento podem ser utilizados e, dentre eles, o emprego das macrófitas aquáticas em alagados artificiais representa um sistema bastante estudado para aquicultura, apresentando eficiência na redução das concentrações de poluentes inorgânicos, metais pesados, substâncias tóxicas, além de microrganismos patogênicos e/ou indicadores, como os coliformes termotolerantes (por exemplo, Escherichia coli) (ALMEIDA \& ALMEIDA, 2006; DINIZ et al., 2005; SANTOS \& CAMARGO, 2015; OTTOSON et al., 2005; PINTO et al., 2009).

Sistemas de tratamento de efluentes que utilizam macrófitas aquáticas, chamados constructed wetlands (CW) ou alagados artificiais, são sistemas ecológicos de engenharia em que o formato, as características hidráulicas e as espécies vegetais visam imitar os processos que ocorrem em um alagado natural (GOPAL, 1999). Nesse tipo de sistema, os poluentes são removidos pela combinação de processos físicos, químicos e biológicos, incluindo sedimentação, precipitação, adsorção de partículas, assimilação pelo tecido da planta e transformação bacteriana (BRIX \& SCHIERUP, 1989).

A utilização de CW representa uma opção para o tratamento de diversos tipos de efluentes, tendo como vantagens baixo custo de implementação e consumo de energia, simplicidade de instalação e operação, além de menor uso de processos químicos intensivos (CUNHA, 2006). O funcionamento correto de um CW depende da interação entre as plantas utilizadas, substrato e microrganismos em relação ao tipo e à estrutura do efluente a ser tratado (LETO et al., 2013).

A remoção de E. coli em um sistema tipo CW é atribuída à adsorção, sedimentação e inativação (BOUTILIER et al., 2009); assim, é possível que a utilização de macrófitas de tipos ecológicos diferentes tenha um efeito complementar, uma vez que essas plantas ocupam espaços diferentes na coluna d'água e utilizam diferentes estratégias de crescimento, de obtenção de nutrientes e de sobrevivência. Assim, o objetivo do trabalho foi avaliar a contaminação por Escherichia coli em um viveiro de criação de pacu, Piaractus mesopotamicus (Holmberg, 1887), e sua remoção do efluente por tratamento, utilizando um sistema tipo CW contendo macrófitas aquáticas de três tipos ecológicos diferentes (flutuante, submersa e emergente).

\section{MATERIAIS E MÉTODOS}

O trabalho foi realizado no Centro de Aquicultura da Universidade

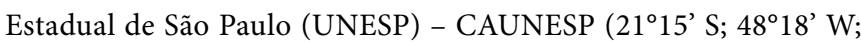
$595 \mathrm{~m}$ acima do nível do mar), Campus de Jaboticabal/SP, no período de 31 de agosto a 23 de novembro de 2010 . O viveiro possuía $200 \mathrm{~m}^{2}$ com profundidade média de $1,1 \mathrm{~m}$. O abastecimento foi realizado com água proveniente de uma represa do CAUNESP, com taxa de renovação média de $23,1 \%$ ao dia.

$\mathrm{O}$ viveiro foi divido em quatro parcelas, e cada duas parcelas foram povoadas com pacu (Piaractus mesopotamicus) de dois tamanhos diferentes, sendo 50 peixes com 400 e $500 \mathrm{~g}$ cada e 150 jovens com até $100 \mathrm{~g}$ cada. Os peixes foram alimentados com ração extrusada, composta por $32 \%$ de proteína e $325 \mathrm{mg}$ de vitamina C por $\mathrm{kg}$, fabricada nos diâmetros de 4-6 mm e 6-8 mm. A composição da ração foi de $6,5 \%$ de extrato etéreo, $7,0 \%$ de matéria fibrosa, 10,0\% de matéria mineral, $1,2 \%$ de cálcio e $0,6 \%$ de fósforo.

O sistema de tratamento do efluente foi composto por tanques de plástico polietileno em formato circular, com volume de 2.000 litros cada, com três repetições, consistindo em um sistema de fluxo contínuo com quatro tanques na seguinte ordem: o tanque um (T1) sem planta, tratado somente com sedimentação; tanque dois (T2), contendo Eichhornia crassipes (Mart.) Raf. 1837 (aguapé); tanque três (T3), contendo Ceratophyllum demersum Linnaeus, 1753 (candelabro-aquático); e tanque quatro (T4), contendo Typha domingensis Pers. (taboa). O tempo médio de residência da água em todo o sistema de tratamento foi de $12 \pm 1$ horas. As três espécies de macrófitas utilizadas neste estudo foram selecionadas por apresentarem tipos ecológicos diferentes entre si, serem cosmopolitas e já terem sido amplamente estudadas individualmente, inclusive em trabalhos sobre tratamentos de efluentes.

Os tanques de sedimentação foram mantidos sempre tampados, com a finalidade de evitar crescimento de fitoplâncton. Nos tanques contendo E. crassipes (T2), foi realizado povoamento com biomassa inicial, preenchendo aproximadamente $80 \%$ da superfície para evitar a competição com fitoplâncton. Para implantação do C. demersum foram fixados seis ramos da planta em vaso com terra e alocados 12 vasos por repetição, forçando, dessa forma, a planta a ocupar um maior espaço na coluna d'água com seu crescimento. $\mathrm{O}$ tanque com T. domingensis (T4) foi preenchido com solo, areia, pedrisco e brita, com proporção 2:1:1:2, respectivamente, com a finalidade de obtenção de um solo 
filtrante. No fundo do tanque foi implantado um cano de drenagem envolto em tela para evitar entupimentos.

A amostragem de água foi realizada em frascos de vidros esterilizados (500 ml), entre oito e nove horas da manhã, quinzenalmente, durante três meses, nos dias 1, 15, 30, 45, 60, 75 e 90 a partir do início do experimento. Os pontos de amostragem foram o abastecimento do viveiro (Ab), o efluente (Ef) e após cada etapa do tratamento (T1, T2, T3 e T4), sendo o ponto após o T4 considerado o efluente tratado.

As determinações do número mais provável (NMP) de Escherichia coli na água foram realizadas segundo a técnica do substrato cromogênico-fluorogênico-hidrolisável, em que $100 \mathrm{ml}$ da amostra ou de sua diluição foram misturados ao meio de cultura (Colilert - IDEXX Quanti-Tray $\left.{ }^{\mathrm{TM}}\right)$. Após homogeneização, a mistura foi transferida para a cartela (IDEXX Quanti-Tray ${ }^{\mathrm{TM}}$ ) e selada em seladora específica, modelo 1925.00 1E-E (IDEXX Quanti-Tray ${ }^{\mathrm{TM}}$ ). Em seguida, as cartelas foram incubadas a $35^{\circ} \mathrm{C}$ por 24 horas. O NMP de Escherichia coli foi determinado pela contagem das células que apresentaram fluorescência após exposição da cartela aos raios ultravioleta. O valor do NMP $100 \mathrm{ml}^{-1}$ foi obtido com a utilização de tabela específica (APHA, 2005).

A partir do segundo dia de amostragem também foi determinado o NMP de E. coli nas folhas de C. demersum, raízes de E. crassipes e solo da caixa que continha T. domingensis. Para isso, três pontos aleatórios de cada caixa foram amostrados e homogeneizados, sendo pesados $25 \mathrm{~g}$ das plantas e $2 \mathrm{~g}$ de solo, acrescentado a $225 \mathrm{ml}$ e $18 \mathrm{ml}$, respectivamente, de água peptonada. A partir das diluições $10^{-1}$ a $10^{-5}$ das amostras, foram inoculados com $1 \mathrm{ml}$ três tubos de caldo lauril sulfato triptose com tubo de Durham invertido. Após a inoculação, esses tubos foram incubados a $35^{\circ} \mathrm{C}$ entre 24 e 48 horas e considerados positivos aqueles que apresentaram crescimento bacteriano caracterizado por turvação do meio e produção de gás (APHA, 2005).

A partir de cada tubo de caldo lauril sulfato triptose com resultado positivo no teste presuntivo, foram inoculados, com uma alça estéril, tubos correspondentes contendo caldo Fluorocult ${ }^{\circledR}$ com tubo de Durham invertido. A incubação foi realizada a $35^{\circ} \mathrm{C}$ por 24 horas, sendo considerados positivos os tubos que se revelaram com crescimento bacteriano, presença de gás e fluorescência após se incidir luz ultravioleta $(366 \mathrm{~nm})$. Os resultados foram obtidos por comparação dos números de tubos positivos com os dados da tabela de Hoskins, sempre considerando três diluições consecutivas, a partir da maior diluição, com três tubos positivos, determinando o NMP por grama de amostra (APHA, 2005).

A porcentagem de remoção de E. coli (\%R) foi calculada para cada ponto amostral em relação ao abastecimento do viveiro. A diferença entre os pontos de amostragem, a influência do tempo e a interação ponto e tempo foi testada pelo General Linear Models (GLM), utilizando análise de variância (ANOVA fatorial). As diferenças significativas foram comparadas pelo teste de comparações múltiplas de Fisher (LSD) (STATISTICA versão 9.1, Stat Soft, Inc.).

\section{RESULTADOS}

Na média de todos os dias amostrais, a fonte de abastecimento apresentou o maior NMP de Escherichia coli e o ponto após o tratamento com E. carassipes (T2), o menor. Os tratamentos que utilizavam substrato (T3 e T4) apresentaram alto valor de NMP de E. coli nas três primeiras semanas de amostragem, o que demonstrou que o solo utilizado estava contaminado por E. coli, causando nesse período o acréscimo na água em vez da remoção. Contudo, foi verificada uma diminuição do NMP de E. coli nesses pontos no decorrer do tempo (Tabela 1).

A análise dos dados demonstrou que ocorreram diferenças entre os tratamentos, entre os dias amostrais do experimento e a interação entre os dois. O abastecimento apresentou maior NMP de E. Coli, seguido pelo efluente do viveiro. $\mathrm{O}$ tratamento $\mathrm{T} 2$ apresentou menor presença de E. coli e os tratamentos T1, T3 e T4 não apresentaram diferenças entre si. Quanto à influência do tempo, observou-se que o dia 45 apresentou menores índices de contaminação por E. coli, seguido pelos dias 60 e 75. Em contrapartida, os dias 1, 15, 30 e 90 apresentaram os

Tabela 1 - Médias de número mais provável (NMP) de Escherichia coli em $100 \mathrm{ml}^{-1}$ e porcentagem de remoção (\%R) de $E$. coli no abastecimento $(\mathrm{Ab})$, efluente $(\mathrm{Ef})$ e tratamento com wetland nas etapas de sedimentação (T1), Eichhornia crassipes (T2), Ceratophyllum demersum (T3) e Typha domingensis (T4).

\begin{tabular}{|c|c|c|c|c|c|c|c|}
\hline Dias & Unidade & $A b$ & Ef & $\mathrm{T} 1$ & $\mathrm{~T} 2$ & T3 & T4 \\
\hline \multirow{2}{*}{1} & NMP $100 \mathrm{ml}^{-1}$ & 37,1 & 12,1 & 5,5 & 3,4 & 207,7 & 649,1 \\
\hline & $\% R$ & 0,0 & 67,4 & 85,3 & 90,7 & $-459,7$ & $-1649,6$ \\
\hline \multirow{2}{*}{15} & NMP $100 \mathrm{ml}^{-1}$ & 60,2 & 48,6 & 23,5 & 6,5 & 110,9 & 56,4 \\
\hline & $\% \mathrm{R}$ & 0,0 & 19,3 & 60,9 & 89,2 & $-84,3$ & 6,2 \\
\hline \multirow{2}{*}{30} & NMP $100 \mathrm{ml}^{-1}$ & 871,9 & 54,9 & 38,4 & 13,6 & 9,4 & 67,9 \\
\hline & $\% R$ & 0,0 & 93,7 & 95,6 & 98,4 & 98,9 & 92,2 \\
\hline \multirow{2}{*}{45} & NMP $100 \mathrm{ml}^{-1}$ & 53,9 & 11,9 & 6,6 & 0,7 & 3,1 & 5,2 \\
\hline & $\% \mathrm{R}$ & 0,0 & 77,8 & 87,8 & 98,8 & 94,3 & 90,3 \\
\hline \multirow{2}{*}{60} & NMP $100 \mathrm{ml}^{-1}$ & 182,4 & 13,5 & 7,3 & 3,6 & 6,6 & 3,6 \\
\hline & $\% R$ & 0,0 & 92,6 & 96,0 & 98,0 & 96,4 & 98,0 \\
\hline \multirow{2}{*}{75} & NMP $100 \mathrm{ml}^{-1}$ & 63,1 & 89,1 & 10,4 & 6,3 & 3,1 & 2,7 \\
\hline & $\% R$ & 0,0 & $-41,2$ & 83,5 & 90,0 & 95,1 & 95,7 \\
\hline \multirow{2}{*}{90} & NMP $100 \mathrm{ml}^{-1}$ & 201,9 & 672,5 & 820,3 & 45,8 & 4,9 & 7,3 \\
\hline & $\% R$ & 0,0 & $-233,1$ & $-306,3$ & 77,3 & 97,6 & 96,4 \\
\hline \multirow{2}{*}{ Geral } & NMP $100 \mathrm{ml}^{-1}$ & 210,1 & 128,9 & 130,3 & 11,4 & 49,4 & 113,2 \\
\hline & $\% R$ & 0,0 & 38,6 & 38,0 & 94,6 & 76,5 & 46,1 \\
\hline
\end{tabular}


maiores índices de contaminação e não diferiram entre si (Tabela 2). O maior NMP ocorrido nos dias iniciais deve-se à alta contaminação presente no solo dos tratamentos T3 e T4.

Apesar de não ter sido observada diferença na comparação entre as médias de T1, T3 e T4, a dinâmica do NMP de E. coli do tratamento T1 foi semelhante à verificada no efluente do viveiro, enquanto os tratamentos T3 e T4 apresentaram grande contaminação nos primeiros dias amostrais e uma alta remoção nos últimos. O tratamento T2 apresentou remoção eficiente de E. coli durante todo experimento, e esse ponto apresentou a melhor média de remoção total; contudo, foi verificada uma tendência de aumento do NMP de E. coli nos últimos dias amostrais (Figura 1).

Não foi identificada tendência do NMP de E. coli nas amostras das plantas e solo, e também não ocorreu relação com o NMP de E. coli nas amostras de água. Durante a semana 2, foi observada maior média de NMP de E. coli por grama de amostra, evidenciando a contaminação do solo no início do experimento (Tabela 3).

\section{DISCUSSÃO}

De acordo com a Resolução no 357 do CONAMA (BRASIL, 2005), todas as amostras estavam de acordo com os limites estabelecidos de máximo de 1000 NMP de Escherichia coli em 100 ml de amostra para águas de classe dois, indicadas para desenvolvimento de aquicultura.

A média de NMP de E. coli na água foi menor no efluente do viveiro do que na fonte de abastecimento (Tabelas 1 e 2); o viveiro

Tabela 2 - Análise de variância (ANOVA) e teste LSD - Fisher de comparação de médias do NMP de Escherichia coli em 100 ml de amostra nos pontos de abastecimento (Ab), efluente (Ef) e tratamento com wetland, sedimentação (T1), Eichhornia crassipes (T2), Ceratophyllum demersum (T3) e Typha domingensis (T4) ao longo dos dias amostrais.

\begin{tabular}{|c|c|c|c|}
\hline ANOVA Fatorial & $\mathrm{GL}$ & $\mathrm{p}$ & $\mathrm{F}$ \\
\hline Ponto & 5 & $<0,001$ & 37,432 \\
\hline Dias amostrais & 6 & $<0,001$ & 15,471 \\
\hline Ponto $\times$ dias amostrais & 30 & $<0,001$ & 8,291 \\
\hline \multicolumn{4}{|c|}{ Comparação de Médias - Fisher LSD* } \\
\hline \multicolumn{2}{|l|}{ Tratamento } & \multicolumn{2}{|c|}{ Dias amostrais } \\
\hline$A b$ & $a_{-}$ & 1 & $a_{-}$ \\
\hline Ef & $b_{-}$ & 15 & $a_{-}$ \\
\hline T1 & $-C_{-}$ & 30 & $a_{-}$ \\
\hline T2 & - d & 45 & - C \\
\hline Т3 & $C_{-}$ & 60 & $\mathrm{~b}_{-}$ \\
\hline \multirow[t]{2}{*}{$\mathrm{T} 4$} & $C_{-} c_{-}$ & 75 & $b_{-}$ \\
\hline & & 90 & $a_{-}$ \\
\hline
\end{tabular}

*Valores seguidos de mesma letra na mesma coluna não diferem estatisticamente ao nível de $5 \%$ de significância, $a>b>c>d$. GL = graus de liberdade. pode exercer remoção devido a processos de sedimentação e competição com outros organismos (SUHALIM et al., 2008). Além disso, a água de abastecimento era proveniente de uma represa que permite o acesso de diversos animais, podendo ocorrer a contaminação da água de abastecimento por fezes. Inclusive, durante o experimento, foi relatado e observado um grupo de capivaras frequentando a represa utilizada para abastecimento.

Os pontos de abastecimento e efluente do viveiro apresentaram uma dinâmica semelhante quanto à presença de E. coli (Figura 1), que indica uma intermitência da contaminação por E. coli no abastecimento e uma tendência de aumento da contaminação nesses dois pontos durante o fim do experimento. A variação temporal da contaminação desses dois locais por E. coli pode ter ocorrido devido à frequência de animais na represa de abastecimento ou por ocorrência

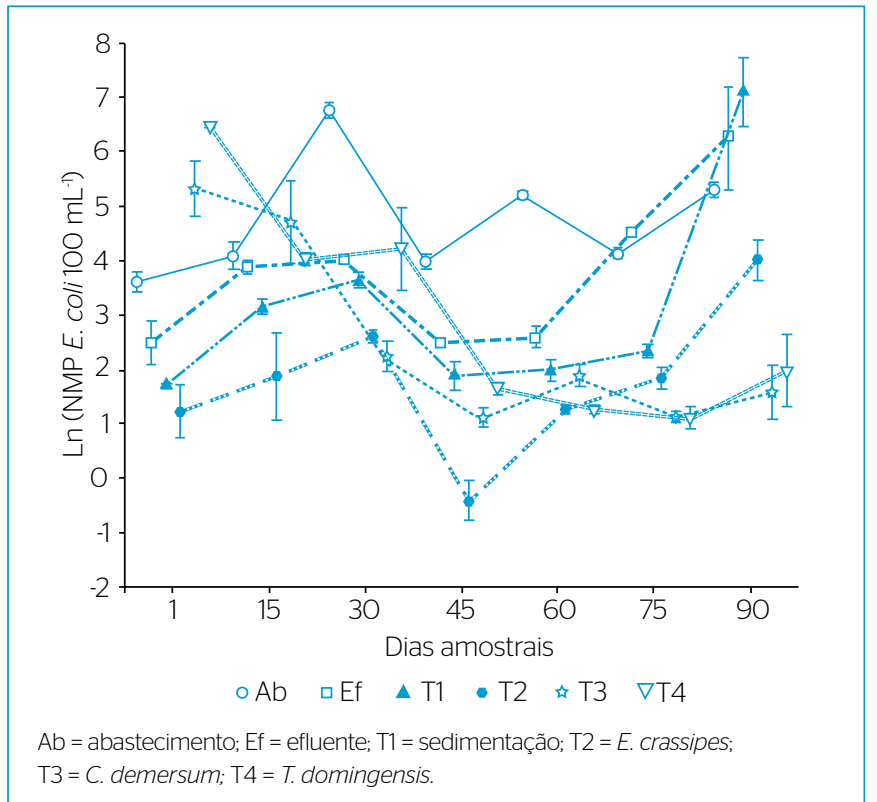

Figura 1 - Dinâmica do número mais provável (NMP) de Escherichia coli em $100 \mathrm{ml}$ de água na criação de pacu e nas etapas do tratamento do efluente. Valores apresentados no formato $\mathrm{Ln}$ (NMP E. coli $100 \mathrm{ml}^{-1}$ ) com os respectivos desvios padrão.

Tabela 3 - Médias do número mais provável (NMP) de Escherichia coli nas amostras de água (NMP $100 \mathrm{ml}^{-1}$ ) e nas amostras de plantas e solo (NMP $\mathrm{g}^{-1}$ ) dos tratamentos com Eichhornia crassipes (T2), Ceratophyllum demersum (T3) e Typha domingensis (T4) no decorrer dos dias amostrais.

\begin{tabular}{l|c|c|c|c|c|c}
\multirow{2}{*}{ Dias amostrais } & \multicolumn{2}{|c|}{ T2 } & \multicolumn{2}{c|}{ T3 } & \multicolumn{2}{c}{ T4 } \\
\cline { 2 - 7 } & Agua & Plantas & Água & Plantas & Água & Solo \\
\hline 15 & 6,5 & 24,0 & 110,9 & 0,0 & 56,4 & 407,3 \\
\hline 30 & 13,6 & 63,0 & 9,4 & 4,2 & 22,6 & 15,5 \\
\hline 45 & 0,7 & 0,1 & 3,1 & 0,1 & 5,2 & 8,0 \\
\hline 60 & 3,6 & 0,1 & 6,6 & 0,1 & 3,6 & 1,4 \\
\hline 75 & 6,3 & 0,8 & 3,1 & 1,1 & 3,1 & 1,2 \\
\hline 90 & 55,2 & 1,0 & 4,9 & 0,3 & 7,3 & 0,0 \\
\hline
\end{tabular}


de chuvas, que contaminariam a represa ou o viveiro por meio do escoamento superficial (SERVAIS et al., 2007). Além disso, a tendência de aumento da contaminação durante os últimos dias amostrais pode estar relacionada a climas mais quentes e chuvosos.

Em sistemas de cultivos de aquicultura, a lagoa de sedimentação representa a principal opção de tratamento de efluentes antes do despejo no corpo hídrico receptor. Contudo, fica evidente que picos de contaminação, como ocorreram nas últimas semanas do experimento (Figura 1), podem não suplantar a capacidade de remoção de E. coli apenas por sedimentação, demonstrando a importante contribuição das macrófitas aquáticas nesse processo.

O sistema CW remove os microrganismos por meio de adsorção, sedimentação e inativação, sendo que o principal processo de remoção é a inativação dos microrganismos (BOUTILIER et al., 2009). Além disso, existem diversos registros de incorporação de E. coli nas raízes de algumas plantas (ERICKSON et al., 2014; WARRINER et al., 2003), sendo que o mesmo pode ter ocorrido no sistema de tratamento com macrófitas. Outros fatores, como as estações do ano e as características físico-químicas da água, podem influenciar a eficiência da remoção realizada pelas $\mathrm{CW}$, uma vez que influenciam o crescimento das plantas e a sobrevivência de microrganismos patogênicos (HAMAAMIN et al., 2014; MCLAIN \& WILLIAMS, 2008).

A Eichhornia crassipes foi a macrófita aquática que apresentou a melhor média de remoção de E. coli, mesmo localizada em ponto intermediário do sistema de tratamento (Tabelas 1 e 2). Segundo Diniz et al. (2005), as macrófitas flutuantes exercem efeito filtrador significativo sobre bactérias indicadoras de poluição fecal devido às suas raízes ficarem cobertas por material orgânico e mucilaginoso, permitindo a formação da comunidade perifítica. As raízes das plantas flutuantes também favorecem a diversidade microbiana, aumentando a competição e reduzindo a quantidade de bactérias indicadoras de contaminação fecal (HENCH et al., 2003; WERKER et al., 2002). Contudo, macrófitas flutuantes também podem favorecer a sobrevivência de E. coli, fornecendo locais de adsorção, sombreamento contra radiação ultravioleta e diminuição da troca de oxigênio na superfície, o que pode diminuir a população de zooplâncton predadores (MACINTYRE et al., 2006).

Quando a contaminação do substrato presente nos tanques T3 e T4 diminuiu seu efeito, todas as etapas de tratamento que continham macrófitas demonstraram grande eficiência na remoção de E. coli, apresentando remoção média de 95\% do NMP de E. coli no efluente tratado final. O fato de o solo estar contaminado com E. coli (Tabela 3) prejudicou os resultados iniciais, diminuindo a eficiência média de tratamento das etapas T3 e T4 (Tabela 1). Ao considerar a porcentagem de remoção de E. coli somente dos três últimos dias amostrais, a eficiência de remoção de cada etapa foi: $\mathrm{Ef}=-60,5 \%, \mathrm{~T} 1=-42,2 \%$, $\mathrm{T} 2=88,4 \%$, T3 $=96,3 \%$ e T4 $=96,7 \%$. Dessa forma, nas últimas semanas, o efluente do viveiro e o tanque de sedimentação apresentaram maior NMP de E. coli do que o abastecimento (Tabela 1 e Figura 1). No decorrer do tempo também ocorreu diminuição da eficiência de remoção pela E. crassipes, enquanto a eficiência nos tratamentos finais (C. demersum e T. domingensi) aumentou consideravelmente (Figura 1).

A diminuição na eficiência de remoção apresentada pela E. crassipes nesse experimento já foi relatada em outros trabalhos com outras macrófitas flutuantes, e foi atribuída a diminuição do vigor da planta e acúmulo de sedimento (COLEMAN et al., 2001; HENCH et al., 2003). Isso evidencia uma vantagem da utilização de uma maior diversidade de espécies no sistema de tratamento que, além de ter efeito complementar na remoção de E. coli, mantêm a eficiência do sistema como um todo, mesmo quando observada diminuição da eficiência em alguma outra etapa do tratamento.

Além da complementação do tratamento em cada semana amostral, a diversidade de macrófitas pode aumentar a eficiência do sistema devido às diferentes espécies apresentarem maior eficiência de remoção de E. coli em períodos diferentes. O tratamento com E. crassipes apresentou maior eficiência de remoção de E. coli entre 30 e 60 dias após a implementação do sistema, sendo observada diminuição gradual da eficiência após esse período. Os tanques com C. demersum e T. domingensis tiveram um período de remoção eficiente mais prolongado, a partir de 30 e 45 dias, respectivamente, após a implantação do sistema até o final do experimento. É importante ressaltar que mesmo que seja mínima, sistemas de tratamento com macrófitas necessitam de manutenção, como a remoção de biomassa vegetal quando o crescimento chega à capacidade de suporte do tanque. Dessa forma, após 60 dias da implementação do sistema, algum tipo manutenção (por exemplo, limpeza do sedimento, retirada de biomassa etc.) poderia ter sido feito no tanque contendo E. crassipes visando à recuperação da eficiência de remoção nessa etapa. Enquanto isso, as etapas com as demais macrófitas mostraram-se fundamentais para a manutenção da qualidade do efluente.

Trabalhos com outros tipos de efluentes obtiveram resultados com eficiência próxima da obtida pelo sistema de tratamento proposto. Por exemplo, Diniz et al. (2005), trabalhando com três espécies de macrófitas, verificaram reduções de coliformes termotolerantes entre 35 e 98\% após a passagem da água por um banco de macrófitas formado por E. crassipes, Pistia stratiotes e Typha spp. Van Kaick (2002) obteve redução de até $94 \%$ dos coliformes fecais em um sistema de tratamento com zona de raízes e atribuiu a redução à morte natural dos microrganismos em ambiente desfavorável e ao efeito tóxico de secreções radiculares sobre eles. Almeida e Almeida (2006) relataram remoção acima de 99,5\% de coliformes totais e fecais de efluente de esgoto com a utilização de zona de raízes com fluxo subsuperficial das macrófitas Typha angustifolia, Hedychium coronarium e Coixlacryma jobi. Pinto et al. (2009) desenvolveram um trabalho com macrófitas flutuantes para tratamento de efluentes de carcinicultura e verificaram 
redução da contaminação por E. coli de $88,23 \%$ utilizando E. crassipes, $76,47 \%$ utilizando Salvinia molesta e 78,82\% utilizando uma interação entre E. crassipes e S. molesta.

Assim, concluiu-se que a água de abastecimento contaminada por Escherichia coli pode chegar até o viveiro de criação de pacu ou também pode ocorrer a contaminação dentro do próprio viveiro. A água contaminada atingirá o corpo hídrico receptor por meio de um efluente não tratado. A utilização de um sistema de tratamento de efluentes do tipo constructed wetland (alagados artificiais), contendo três espécies de macrófitas aquáticas de tipos ecológicos diferentes (Eichhornia crassipes, Ceratophyllum demersum e Typha domingensis), mostrou eficiência média de remoção de $46 \%$ do número mais provável de E. coli. Contudo, essa remoção média do experimento foi prejudicada devido à presença de $E$. coli nas amostras de solo utilizado como substrato dos tanques de tratamentos com $C$. demersum e $T$. domingensis. Com a diminuição do efeito da contaminação do solo no decorrer do experimento, a real eficiência do sistema pôde ser comprovada, uma vez que a remoção média de $E$. coli foi de $95 \%$ quando considerados os dias amostrais a partir de um mês de estabilização do sistema. A etapa do tratamento que apresentou maior eficiência na remoção de E. coli durante todo o experimento foi o tanque contendo E. crassipes, justamente porque nesse tanque não foi utilizado solo durante a instalação. Porém, nos dias finais do experimento, foi observada diminuição da eficiência de remoção nos tanques contendo E. crassipes, sendo as etapas finais (C. demersum e T. domingensis) fundamentais para a manutenção da eficiência de remoção do sistema como um todo, evidenciando uma complementação do tratamento por macrófitas aquáticas de tipos ecológicos diferentes. Como sistemas de tratamento baseados em alagados artificiais apresentam baixo custo e fácil instalação e manutenção, aliados a uma eficiente remoção de organismos indicadores de contaminação, esses sistemas representam uma alternativa viável para empreendimentos de aquicultura.

\section{REFERÊNCIAS}

ALMEIDA, R.A.; ALMEIDA, N.A.M. (2006) Remoção de coliformes do esgoto por meio de espécies vegetais. Revista Eletrônica de Enfermagem, v. 7, n. 3, p. 306-317.

APHA. AMERICAN PUBLIC HEALTH ASSOCIATION. (2005) Standard methods for the examination of water and wastewater. 2Oth ed. Washington: APHA.

AYROZA, D.M.M.R.; NOGUEIRA, M.G.; DA SILVA AYROZA, L.M.; CARVALHO, E.D.; FERRAUDO, A.S.; CAMARGO, A.F.M. (2013) Temporal and spatial variability of limnological characteristics in areas under the influence of tilapia cages in the Chavantes Reservoir, Paranapanema River, Brazil. Journal of the World Aquaculture Society, v. 44, n. 6, p. 814-825.

BOUTILIER, L.; JAMIESON, R.; GORDON, R.; LAKE, C.; HART, W. (2OO9) Adsorption, sedimentation, and inactivation of E. coli within wastewater treatment wetlands. Water Research, v. 43, n. 17, p. 4370-4380.

BRASIL. Conselho Nacional do Meio Ambiente (CONAMA). (2005) Resolução no 357, de 17 de março de 2005. Dispõe sobre a classificação dos corpos de água e diretrizes ambientais para o seu enquadramento, bem como estabelece as condições e padrões de lançamento de efluentes, e dá outras providências. Disponível em: <http://www.mma. gov.br/port/conama/res/resO5/res35705.pdf>. Acesso em: 22 ago. 2016.

BRIX, H.; SCHIERUP, H. (1989) The use of aquatic macrophytes in water-pollution control. Ambio. Stockholm, v. 18, n. 2, p. 100-107.

COLEMAN, J.; HENCH, K.; GARBUTT, K.; SEXSTONE, A.; BISSONNETTE, G.; SKOUSEN, J. (2001) Treatment of domestic wastewater by three plant species in constructed wetlands. Water, Air, \& Soil Pollution, v. 128, n. 3, p. 283-295.
CUNHA, C.A.G. (2006) Análise de eficiência de um sistema combinado de alagados construidos na melhoria da qualidade das águas, 2006. 174 f. Dissertação (Mestrado). Universidade de São Paulo - Ciências da Engenharia Ambiental, São Carlos.

DINIZ, C.R.; CEBALLOS, B.S.O.; BARBOSA, J.E.D.L.; KONIG, A. (2005) Uso de macrófitas aquáticas como solução ecológica para melhoria da qualidade de água. Revista Brasileira de Engenharia Agrícola e Ambiental, v. 9, n. Suplemento, p. 226-230.

ERICKSON, M.C.; WEBB, C.C.; DAVEY, L.E.; PAYTON, A.S.; FLITCROFT, I.D.; DOYLE, M.P. (2O14) Biotic and abiotic variables affecting internalization and fate of Escherichia coli 0157:H7 isolates in leafy green roots. Journal of food protection, v. 77, n. 6, p. 872-879.

GATTI JUNIOR, P.; ASSUNÇÃO, A.W.A.; BALDIN, J.C.; AMARAL, L.A (2014) Microbiological quality of whole and filleted shelf-tilapia. Aquaculture, v. 433, p. 196-200.

GOPAL, B. (1999) Natural and constructed wetlands for wastewater treatement: potentials and problems. Water Science and Technology, v. 40, n. 3, p. 27-35.

HAMAAMIN, Y.A.; ADHIKARI, U.; NEJADHASHEMI, A.P.; HARRIGAN T.; REINHOLD, D.M. (2014) Modeling Escherichia coli removal in constructed wetlands under pulse loading. Water Research, v. 50, p. 441-454.

HENCH, K.R.; BISSONNETTE, G.K.; SEXSTONE, A.J.; COLEMAN, J.G.; GARBUTT, K.; SKOUSEN, J.G. (2003) Fate of physical, chemical, and microbial contaminants in domestic wastewater following treatment by small constructed wetlands. Water Research, v. 37, n. 4, p. 921-927. 
LETO, C.; TUTTOLOMONDO, T.; LA BELLA, S.; LEONE, R.; LICATA, M. (2013) Effects of plant species in a horizontal subsurface flow constructed wetland - phytoremediation of treated urban wastewater with Cyperus alternifolius L. and Typha latifolia L. in the West of Sicily (Italy). Ecological Engineering, v. 61, p. 282-291.

LORENZON, C.S.; GATTI JUNIOR, P.; NUNES, A.P.; PINTO, F.R.; SCHOLTEN, S.N.; HONDA, S.N.; DO AMARAL, L.A. (2O10) Perfil microbiológico de peixes e água de cultivo em pesque-pagues situados na região nordeste do Estado de São Paulo. Arquivos do Instituto Biológico, v. 77, n. 4, p. 617-624.

MACINTYRE, M.E.; WARNER, B.G.; SLAWSON, R.M. (2006) Escherichia coli control in a surface flow treatment wetland. Journal of Water and Health, v. 4, n. 2, p. 211-214.

MCLAIN, J.E.T.; WILLIAMS, C.F. (2008) Seasonal variation in accurate identification of Escherichia coli within a constructed wetland receiving tertiary-treated municipal effluent. Water research, v. 42, n. 15 , p. $4041-4048$

OTTOSON, J.; NORSTRÖM, A.; DALHAMMAR, G. (2005) Removal of micro-organisms in a small-scale hydroponics wastewater treatment system. Letters in applied microbiology, v. 40, n. 6, p. 443-447.

PINTO, F.R.; HENARES, M.N.P.; CRUZ, C:; AMARAL, L.A. (2009) Remoção de Escherichia coli de efluentes de carcinicultura por macrófitas aquáticas flutuantes. ARS Veterinária, v. 25, n. 3, p. 147-150.

SANTOS, A.A.O.; CAMARGO, A.F.M. (2015) Constructed wetlands for treatment of harvest effluents from grow-out ponds of the Amazon river prawn. Aquaculture Research, v. 46, n. 11, p. 2676-2684.

SERVAIS, P; GARCIA-ARMISEN, T; GEORGE, I.; BILLEN, G. (2007) Fecal bacteria in the rivers of the Seine drainage network (France): sources, fate and modelling. Science of The Total Environment, v. 375, n. 1-3, p. $152-167$.
STEPHENS, W.W.; FARRIS, J.L. (2004) A biomonitoring approach to aquaculture effluent characterization in channel catfish fingerling production. Aquaculture, v. 241, n. 1, p. 319-330.

SUHALIM, R.; HUANG, Y.W.; BURTLE, G.J. (2008) Survival of Escherichia coli O157:H7 in channel catfish pond and holding tank water. LWT - Food Science and Technology, v. 41, n. 6, p. 1116-1121.

SUHALIM, R.R.; HUANG, Y.W.; CHEN, J. (2007) Interaction of Escherichia coli 0157:H7 E318 cells with the mucus of harvested channel catfish (Ictalurus punctatus). LWT - Food Science and Technology, v. 40, n. 7, p. 1266-1270.

THOMPSON, F.L.; ABREU, P.C.; WASIELESKY, W. (2002) Importance of biofilm for water quality and nourishment in intensive shrimp culture. Aquaculture, v. 203, n. 3-4, p. 263-278.

VAN KAICK, T.S. (2002) Estação de tratamento de esgoto por meio de zona de raízes: uma proposta de tecnologia apropriada para saneamento básico no litoral do Paraná, 2002. 128 f. Dissertação (Mestrado). Universidade Federal do Paraná - Mestrado em Tecnologia, Curitiba.

WARRINER, K.; SPANIOLAS, S.; DICKINSON, M.; WRIGHT, C.; WAITES, W.M. (2003) Internalization of bioluminescent Escherichia coli and Salmonella Montevideo in growing bean sprouts. Journal of Applied Microbiology, v. 95, n. 4, p. 719-727.

WERKER, A.G.; DOUGHERTY, J.M.; MCHENRY, J.L.; VAN LOON, W.A. (2002) Treatment variability for wetland wastewater treatment design in cold climates. Ecological Engineering, v. 19, n. 1, p. 1-11.

YUCEL-GIER, G.; KUCUKSEZGIN, F.; KOCAK, F. (2007) Effects of fish farming on nutrients and benthic community structure in the Eastern Aegean (Turkey). Aquaculture Research, v. 38, n. 3 p. 256-267. 